\title{
Unraveling the genetics of Joubert and Meckel-Gruber syndromes
}

\author{
Katarzyna Szymanska, Verity L. Hartill and Colin A. Johnson* \\ Department of Ophthalmology and Neuroscience, University of Leeds, Leeds, UK
}

Received 27 May 2014

Revised 11 July 2014

Accepted 14 July 2014

\begin{abstract}
Joubert syndrome (JBTS) and Meckel-Gruber syndrome (MKS) are recessive neurodevelopmental conditions caused by mutations in proteins that are structural or functional components of the primary cilium. In this review, we provide an overview of their clinical diagnosis, management and molecular genetics. Both have variable phenotypes, extreme genetic heterogeneity, and display allelism both with each other and other ciliopathies. Recent advances in genetic technology have significantly improved diagnosis and clinical management of ciliopathy patients, with the delineation of some general genotype-phenotype correlations. We highlight those that are most relevant for clinical practice, including the correlation between TMEM67 mutations and the JBTS variant phenotype of COACH syndrome. The subcellular localization of the known MKS and JBTS proteins is now well-described, and we discuss some of the contemporary ideas about ciliopathy disease pathogenesis. Most JBTS and MKS proteins localize to a discrete ciliary compartment called the transition zone, and act as structural components of the so-called "ciliary gate" to regulate the ciliary trafficking of cargo proteins or lipids. Cargo proteins include enzymes and transmembrane proteins that mediate intracellular signaling. The disruption of transition zone function may contribute to the ciliopathy phenotype by altering the composition of the ciliary membrane or axoneme, with impacts on essential developmental signaling including the Wnt and Shh pathways as well as the regulation of secondary messengers such as inositol-1,4,5-trisphosphate (InsP3) and cyclic adenosine monophosphate (cAMP). However, challenges remain in the interpretation of the pathogenic potential of genetic variants of unknown significance, and in the elucidation of the molecular mechanisms of phenotypic variability in JBTS and MKS. The further genetic and functional characterization of these conditions is essential to prioritize patients for new targeted therapies.
\end{abstract}

Keywords: Joubert syndrome, Meckel-Gruber syndrome, primary cilium, transition zone

\section{Introduction}

The primary cilium is a microtubule-based organelle present as a single longitudinal protrusion on the apical surface of most vertebrate cells, where it acts as an "antenna" to receive and transduce chemo- and

${ }^{*}$ Corresponding author: Colin A. Johnson, PhD, Section of Ophthalmology and Neuroscience, Leeds Institute of Molecular Medicine, Wellcome Trust Brenner Building, St. James's University Hospital, Beckett Street, Leeds LS9 7TF, UK. Tel.: +44 (0) 113343 8443; Fax: +44 (0) 113343 8603; E-mail: c.johnson@ leeds.ac.uk. mechanosensory signals. Cilia are derived from the eldest of two centrioles of the centrosome, the cell's microtubule organizing centre. During quiescence, the microtubule organizing centre is redundant and the "mother centriole" can act at the cell surface to organize ciliogenesis, rendering this a cell cycle-dependent process. Primary cilia are regarded as cellular signaling hubs, regulating diverse signaling pathways, including Wnt, Shh, and Notch with particularly important roles during embryonic development and the patterning of the developing neural tube [1]. Defects in primary cilia are associated with a heterogeneous grouping of inherited developmental conditions known as the 
ciliopathies that often present with cystic kidney disease, and other diverse multi-organ phenotypes that affect the central nervous system, eye and skeleton [2]. As a group, ciliopathies, including autosomal dominant polycystic kidney disease, are comparatively common Mendelian inherited conditions with an overall estimated prevalence of 1 in 2,000 [3]. The importance of the primary cilium in health and genetic disease has only become apparent in the last decade, and the processes involved in cilia formation and maintenance remain poorly characterized.

Primary cilia have a complex ultrastructure with compartmentalization of molecular components that combine in functional modules. Components that are required for both the formation and function of the cilium have to be transported from the cytoplasm of the cell by the process of intraflagellar transport (IFT). Ciliopathies are caused by mutations in proteins that are structural or functional components of the primary cilium [2]. The loss of these components can disrupt ciliary functions such as the control of protein entry and exit from the cilium, the possible trafficking of essential ciliary components, and the regulation of signaling cascades and control of the cell cycle. Many proteins that are mutated in ciliopathies are localized to the transition zone (TZ), a compartment of the proximal region of the cilium $[4,5]$. The $\mathrm{TZ}$ anchors the cilium to the plasma membrane, and is thought to act as a "ciliary gate" that both restricts and facilitates the movement of proteins and lipids in and out of the cilium. In particular, a protein complex at the TZ, known as the "MKS-JBTS module", contains many of the proteins mutated in Meckel-Gruber syndrome (MKS) and Joubert syndrome (JBTS) [6, 7].

In this review, we focus on JBTS and MKS as exemplar ciliopathies to provide an overview of their clinical diagnosis, management and molecular genetics. To date, mutations in 24 genes have been described as a cause of JBTS, and 13 for MKS. Both conditions therefore have extreme genetic heterogeneity, display allelism both with each other and other ciliopathies, and have marked variability of phenotypes. This has complicated the delineation of general genotype-phenotype correlations for JBTS and MKS, but we highlight the most relevant for clinical practice and those that provide insights into protein function. Finally, we describe some contemporary insights into the normal function of selected JBTS and MKS ciliary proteins, and discuss how their dysfunction impacts on pathogenic mechanisms in the ciliopathy disease state.

\section{Diagnosis and management}

JBTS is a rare autosomal recessive (AR) neurodevelopmental condition with a prevalence of 1:100,000 [8] and was first described by Marie Joubert in 1969 [9]. Typical cranial magnetic resonance imaging findings, hypotonia, and developmental delay or mental retardation are necessary for the diagnosis [9-11]. Other suggestive features include an irregular breathing pattern (apnea or tachypnea) and abnormal eye movements or oculomotor apraxia [12]. The typical cranial magnetic resonance imaging finding is of a pathognomonic "molar tooth sign" (MTS), which describes cerebellar vermis hypoplasia or aplasia, a fourth ventricle abnormality, elongated superior cerebellar peduncles and a deep interpeduncular fossa [12, 13] (Figs. 1A and 1B). Concurrent central nervous system (CNS) abnormalities may also be present and approximately $10 \%$ of patients have a Dandy-Walker malformation or enlarged posterior fossa [14]. Many affected individuals have dysmorphic facial features and some have polydactyly [8].

A number of variant forms of JBTS have been described (also known as JBTS related disorders or Joubert syndrome related disorders (JSRDs) in older literature) that have additional features such as polydactyly, coloboma, retinal dystrophy, renal cysts, oral frenulae, and hepatic fibrosis [12]. When ocular and renal anomalies occur, this has been described as CORS (cerebellar-ocular-renal syndrome) [15]. $\mathrm{COACH}$ syndrome describes the combination of coloboma, oligophrenia (mental retardation), ataxia, cerebellar vermis hypoplasia and hepatic fibrosis [16].

The prognosis in JBTS is highly variable, with some children dying in infancy, but others surviving with variable developmental outcomes. Around 50\% of children will learn to walk independently, often with a broad-based gait due to truncal ataxia [17]. Recommendations for the appropriate management of JBTS and JSRD have been set out previously [8, 18]. The key features include initiation of a comprehensive, multidisciplinary approach for support, education and physical and occupational therapy. CNS abnormalities may require neurosurgical intervention. Neurological input is required for the management of seizures and regular ophthalmology review is recommended for the diagnosis and correction of eye abnormalities. Monitoring is required for potential complications and includes annual assessment of both renal and hepatic function [18]. 


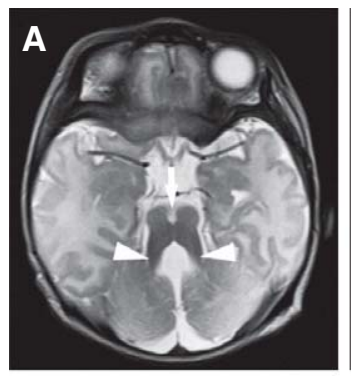

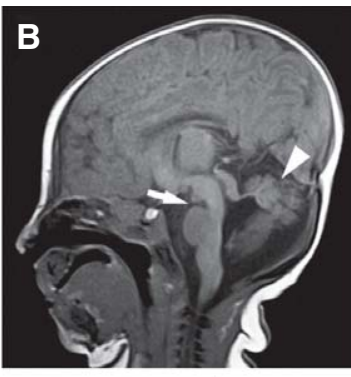
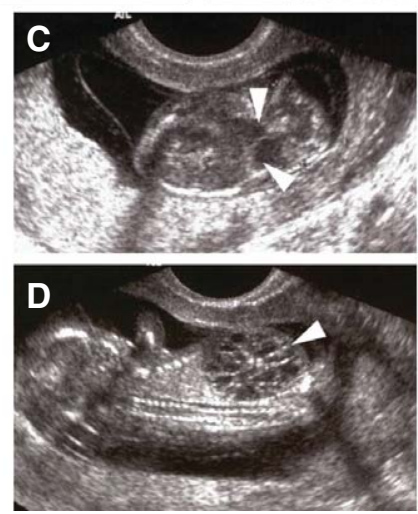
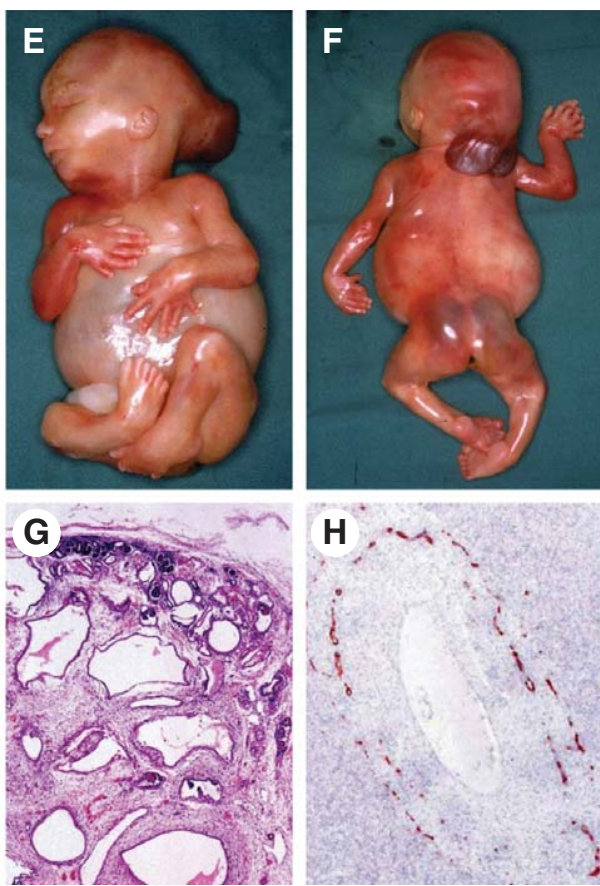

Fig. 1. Clinical features of Joubert syndrome (JBTS) and Meckel-Gruber syndrome (MKS). (A) Axial T2-weighted magnetic resonance imaging scan in a 5-year-old girl showing typical brain anomalies of JBTS, including a deepened interpeduncular fossa (arrow) and elongated superior cerebellar peduncles (arrowheads) that comprise the pathognomonic "molar tooth sign", as well as cerebellar vermis hypoplasis. (B) A sagittal T1weighted magnetic resonance imaging scan showing the deepened interpeduncular fossa (arrow) and cerebellar vermis hypoplasis (arrowhead). The cerebellar hemispheres and brainstem are also hypoplastic. (C-D) Ultrasound findings at 14+/40 weeks of gestation for MKS showing (C) encephalocele (arrowheads) and (D) large cystic kidneys (arrowhead). (E-F) typical external features for a fetus with MKS at 16 wk of gestation showing massive flank masses due to bilateral renal cystic dysplasia, encephalocele and post-axial polydactyly of all limbs. (G) Hematoxylineosin staining of MKS fetal kidney at gestation age 18+/40 showing cystic dysplasia, comprising large, fluid-filled cysts, small cysts and cystic swelling of the proximal tubules and glomeruli, with the absence of normal renal parenchyma. (H) Immunohistochemical staining of MKS fetal liver at gestation age 18+/40 for cytokeratin-19, showing the retention of embryonic bile duct structures (the ductal plate malformation) without the formation of patent bile ducts. Images (A) and (B) are used by kind permission of Dr. Daniel Doherty (Seattle Children's Hospital, University of Washington, USA). Images (C) to (F) are used by kind permission of Dr. Riitta Salonen (Rinnekoti Foundation, Helsinki, Finland) from the Robert J. Gorlin Slide Collection.

MKS is a lethal, AR, congenital anomaly syndrome characterized by posterior fossa abnormalities (most often occipital encephalocele) (Figs. 1C-1F), bilateral enlarged cystic kidneys (Figs. 1D and 1G), polydactyly (Figs. 1E and $1 \mathrm{~F}$ ) and hepatic ductal plate malformation leading to hepatic fibrosis and hepatic cysts (Fig. 1H) [19]. The incidence is estimated to be between $1: 13,250$ and 1:140,000 live births, although increased incidence is recorded in certain ethnic groups including the Finnish and Gujarati-Indian populations [20].

This condition was first reported by Johann F. Meckel in 1822 and subsequently by C.B. Gruber in 1934 [19]. Although the CNS defects are considered to be obligatory features of MKS they have a more variable presentation. CNS anomalies can vary between total craniorachischisis to a partial defect of the corpus callosum, and can include optic nerve hypoplasia [21]. The renal parenchymal histology is often of a typical nature with cystic dysplasia [22] (Fig. 1G). The typical histology of the liver demonstrates a proliferation and dilation of the bile ducts (Fig. 1H), alongside an excess of collagenous connective tissues [22]. These findings are thought to represent arrested development of the hepatic biliary system [23, 24]. Abnormalities of the intrahepatic bile ducts and the presence of cystic kidneys are considered to be consistent features and of important diagnostic value in MKS [22, 24]. Salonen [22] proposed that bilateral multicystic kidneys, hepatic fibrotic changes and a CNS malformation are minimal diagnostic criteria. Other occasional features include post-axial polydactyly (Figs. 1E and $1 \mathrm{~F}$ ), 
shortening and bowing of the long bones, retinal colobomata, pulmonary hypoplasia and situs defects $[19,22]$. Rare features include cystic changes in other organs, such as the lungs and thyroid, abnormalities of the genitalia in male fetuses, microcephaly, congenital heart defects and cleft palate [19, 25-29].

MKS may be associated with an elevated maternal alpha-fetoprotein level during antenatal screening [30]. Antenatal ultrasonography can identify the classic CNS, renal and digital anomalies and the diagnosis can be made before $14 \mathrm{wk}$ gestation in the classical presentation of MKS [30, 31]. Ultrasound diagnosis may be more difficult later in pregnancy due to the presence of oligohydramnios [30]. MKS is invariably lethal either in utero or in the first hour or days of life, usually due to pulmonary hypoplasia. The longest recorded survivor was 28 mo of age [32]. In view of the AR inheritance pattern of this condition, couples with a previously affected child should be offered appropriate genetic counseling with discussion of prenatal diagnosis by chorionic villus sampling if the genetic cause is known, or prenatal ultrasound scan within the first trimester [20, 33].

The differential diagnosis for MKS and JBTS is extensive and includes AR polycystic kidney disease, trisomy 13, Smith-Lemli-Opitz syndrome, hydrolethalus syndrome, Bardet-Biedl syndrome and oral-facial-digital syndrome type 1 (OFD1). The number of differential diagnoses, as well as the extensive allelism between ciliopathies, emphasizes the need for accurate clinical and molecular diagnosis in these conditions [20].

\section{Progress in gene identification}

JBTS and MKS have extreme genetic heterogeneity, and display allelism both with each other and other ciliopathies such as oral-facial-digital syndrome (OFD) and BBS. To date, mutations in 24 genes have been identified as causative for JBTS and 13 as causative for MKS (Table 1). In the following section, we provide a brief overview of historical and contemporary gene discovery studies for these conditions.

\subsection{JBTS}

The first patient affected with JBTS was reported in 1969 [9] and the disease was proposed to be AR in 1977 [34]. The first JBTS locus was reported by Natacci et al. [35], who identified a patient affected with JBTS and a deletion at chromosome $17 \mathrm{p} 11.2$. Subsequently, loci were identified to chromosome 9q [36], 6q23 [37] and $3 q 24$ [38] using the specialized linkage analysis technique of homozygosity mapping in extended consanguineous families. The locus for a variant form of JBTS phenotype that included retinal dysplasia and cystic kidneys (known as "JBTS type B", or "cerebellooculo-renal syndrome"; CORS2) was initially mapped to $11 \mathrm{p} 12-\mathrm{q} 13.3$ [39]. The breakthroughs in gene identification came in 2004, when Parisi et al. [40] identified a deletion involving $N P H P 1$ in a patient affected with JBTS as well as nephronophthisis (a hereditary kidney disease now also described as a ciliopathy) (Table 1 , Fig. 1). In the same year, Ferland et al. [41], investigated JBTS patients with the classical phenotype and linkage to $6 \mathrm{q} 23.2-\mathrm{q} 23.3$, and identified pathogenic mutations in the AHII gene encoding the protein jouberin.

Subsequent genetic studies have provided many seminal insights into the JBTS phenotype and ciliopathies. In 2006, Valente et al. [42] and Sayer et al. [43] identified mutations in CEP290 as a cause of JBTS and substantiated the importance of primary cilia dysfunction. Allelism between JBTS and MKS was demonstrated in 2007 with the identification of mutations in TMEM67 as a cause of JBTS [44], as well as the identification of mutations in RPGRIPIL to be a cause of both JBTS and MKS [45, 46] (Table 1). Mutations in the $A R L 13 B, C C 2 D 2 A$ and INPP5E genes were identified to all cause classical JBTS [47-49]. ARL13B is a small Arf-family GTPase and INPP5E encodes an inositol 1,4,5-trisphosphate (InsP3) 5-phosphatase. InsP3 5-phosphatases hydrolyze InsP3, which acts as a secondary messenger to mobilize calcium from intracellular stores. These findings clearly implicate the dysregulation of embryonic signaling pathways as a cause of the ciliopathy phenotype (Table 1). Further allelism between an unusual X-linked form of JBTS [50] and OFD was demonstrated by mutations in OFD1 [51] (Table 1). Affected males presented with a typical JBTS phenotype, but with additional features, including coloboma, and without a typical MTS.

In recent years, advances in genetic technology (principally, whole-exome sequencing; WES) have enabled a renaissance in gene discovery, often without initial linkage analysis, that has now enabled the study of smaller, non-consanguineous families. A key biological insight from these studies has been the importance of the Tectonic (TCTN) family of 
Table 1

Summary of known JBTS and MKS loci and identified genes

\begin{tabular}{|c|c|c|c|c|c|c|}
\hline Locus & Gene & $\begin{array}{c}\text { Entrez } \\
\text { gene ID }\end{array}$ & Aliases & Cytogenic location & $\begin{array}{l}\text { Founder } \\
\text { mutation(s) }\end{array}$ & Reference \\
\hline JBTS1 & INPP5E & 56623 & CORS1, MORMS & $9 q 34.3$ & & 48,49 \\
\hline JBTS2 & TMEM216 & 51259 & & $11 q 12.2$ & Ashkenazi p.R73L & 52,53 \\
\hline JBTS3 & AHII & 54806 & & $6 q 23.3$ & & 41 \\
\hline JBTS4 & NPHPl & 4867 & NPH1, SLSN1 & $2 q 13$ & & 40 \\
\hline JBTS5 & CEP290 & 80184 & $\begin{array}{l}\text { BBS14, LCA10, MKS4, } \\
\text { NPHP6, POC3, SLSN6 }\end{array}$ & $12 q 21.32$ & & 43 \\
\hline JBTS6 & TMEM67 & 91147 & $\begin{array}{l}\text { MECKELIN, MKS3, } \\
\text { NPHP11 }\end{array}$ & $8 \mathrm{q} 22.1$ & & 44 \\
\hline JBTS7 & RPGRIPIL & 23322 & $\begin{array}{l}\text { CORS3, FTM, MKS5, } \\
\text { NPHP8 }\end{array}$ & $16 q 12.2$ & & 46 \\
\hline JBTS8 & $A R L 13 B$ & 200894 & ARL2L1 & $3 q 11.1$ & & 47 \\
\hline JBTS9 & $C C 2 D 2 A$ & 57545 & MKS6 & $4 p 15.32$ & & 48 \\
\hline JBTS10 & $O F D 1$ & 8481 & JBTS10, CXorf5 & $\mathrm{Xp} 22.2$ & & 51 \\
\hline JBTS11 & TTC21B & 79809 & $\begin{array}{l}\text { ATD4, IFT139, JBTS11, } \\
\text { NPHP12, THM1 }\end{array}$ & $2 q 24.3$ & & 120 \\
\hline JBTS12 & KIF7 & 374654 & & $15 q 26.1$ & & 54 \\
\hline JBTS13 & TCTN1 & 79600 & & $12 q 24.11$ & & 55 \\
\hline JBTS14 & $T M E M 237$ & 65062 & ALS2CR4 & $2 q 33.1$ & & 59 \\
\hline JBTS15 & CEP41 & 95681 & TSGA14 & $7 q 32.2$ & & 57 \\
\hline JBTS16 & TMEM138 & 51524 & & $11 q 12.2$ & & 58 \\
\hline JBTS17 & C5orf 42 & 65250 & & $5 \mathrm{p} 13.2$ & $\begin{array}{c}\text { French-Canadian } \\
\text { p.Arg1336Trp, } \\
\text { p.Ala1564Thr, } \\
\text { c. } 7400+1 \mathrm{G}>\mathrm{A}\end{array}$ & 60 \\
\hline JBTS18 & TCTN3 & 26123 & OFD4, C10orf61 & $10 \mathrm{q} 24.1$ & & 62 \\
\hline JBTS19 & ZNF423 & 23090 & NPHP14, OAZ & $6 q 21$ & & 121 \\
\hline JBTS20 & TMEM231 & 79583 & MKS11 & $16 q 23.1$ & & 63 \\
\hline JBTS21 & $C S P P 1$ & 79848 & CSPP & $8 \mathrm{q} 13.1-\mathrm{q} 13.2$ & & $65-67$ \\
\hline JBTS22 & PDE6D & 5147 & PDED & $2 q 37.1$ & & 64 \\
\hline NA & TCTN2 & 79867 & C12orf38, MKS8 & $12 q 24.31$ & 68 & \\
\hline NA & EXOC8 & 149371 & EXO84, SEC84 & $1 q 42.2$ & 61 & \\
\hline MKS1 & MKS1 & 54903 & BBS13, POC12 & $17 \mathrm{q} 22$ & $\begin{array}{l}\text { Finnish c.1408- } \\
\text { 35_1408-7del29 }\end{array}$ & 71 \\
\hline MKS2 & TMEM216 & 51259 & & $11 \mathrm{q} 12.2$ & Ashkenazi p.R73L & 53 \\
\hline MKS3 & TMEM67 & 91147 & $\begin{array}{l}\text { MECKELIN, JBTS6, } \\
\text { NPHP11 }\end{array}$ & $8 q 22.1$ & $\begin{array}{l}\text { Pakistani } \\
\quad \text { c. } 1575+1 G>A\end{array}$ & 72 \\
\hline MKS4 & CEP290 & 80184 & $\begin{array}{l}\text { BBS14, JBTS5, LCA10, } \\
\text { NPHP6, POC3, SLSN6 }\end{array}$ & $12 q 21.32$ & & 73 \\
\hline MKS5 & $R P G R I P 1 L$ & 23322 & $\begin{array}{l}\text { CORS3, FTM, JBTS7, } \\
\text { NPHP8 }\end{array}$ & $16 q 12.2$ & European p.T625P & 46 \\
\hline MKS6 & $C C 2 D 2 A$ & 57545 & JBTS9 & $4 p 15.32$ & $\begin{array}{l}\text { Finnish } \\
\quad \text { c. } 1762 \mathrm{C}>\mathrm{T}\end{array}$ & 75 \\
\hline MKS7 & NPHP3 & 27031 & SLSN3 & $3 q 22.1$ & & 122 \\
\hline MKS8 & TCTN2 & 79867 & C12orf38 & $12 q 24.31$ & & 76 \\
\hline MKS9 & $B 9 D 1$ & 27077 & MKSR1 & $17 \mathrm{p} 11.2$ & & 77 \\
\hline MKS10 & $B 9 D 2$ & 80776 & MKSR2 & $19 q 13.2$ & & 78 \\
\hline MKS11 & TMEM231 & 79583 & JBTS20 & $16 \mathrm{q} 23.1$ & & 79 \\
\hline NA & EXOC4 & 60412 & SEC8, SEC8L1 & $7 q 33$ & & \\
\hline NA & CSPP1 & 79848 & JBTS21, CSPP & 8q13.1-q13.2 & 66 & \\
\hline
\end{tabular}

Alias names of genes summarize alternative gene symbols and any reported allelism with other ciliopathies (indicated by locus name; NA = not applicable). Any reported founder mutations and references for the primary gene discovery paper(s) are listed. ATD = Asphyxiating thoracic dystrophy; CORS = Cerebellar-ocular-renal syndrome; JBTS = Joubert syndrome; MKS = Meckel-Gruber syndrome; NPHP = Nephronophthisis; $\mathrm{OFD}=$ Oral-facial-digital syndrome; SNLS = Senior-Løken syndrome.

transmembrane proteins and small tetraspanin-like transmembrane proteins (TMEMs) in the pathogenesis of the JBTS phenotype (Table 1). Initial WES studies identified the JBTS genes TMEM216 [52, 53], KIF7 [54], TCTN1 [55, 56], CEP41 [57] and TMEM138 [58]. More recent studies have used WES to identify 
mutations in TMEM237 [59] and C5orf42 as a common cause in French-Canadian JBTS patients [60]. C5ORF42 was also reported to be mutated in a cohort of Saudi-Arabian JBTS patients [56]. The most recently identified JBTS genes include EXOC8 [61], TCTN3 [62], TMEM231 [63], PDE6D [64], CSPP1 [65-67] and TCTN2 [68].

\section{2. $M K S$}

MKS is a Finnish heritage disease, which describes a group of 40 recessive conditions that due to founder effects and genetic isolation are more common in Finns. The first MKS locus, MKS1, was mapped to chromosome 17q21-q24 [29] in endogamous Finnish families using a combination of homozygosity mapping and haplotype analysis to identify regions of linkage disequilibrium. Homozygosity mapping also identified loci (MKS2 and MKS3) at chromosomes $11 \mathrm{q} 13$ [69] and 8q24 [70] respectively, in consanguineous families from the Middle East and the Indian sub-continent. In 2006, Kyttälä et al. [71] identified mutations in the MKS1 gene as a cause of MKS in the Finnish population, whilst Smith et al. [72] identified mutations in TMEM67 in the MKS3 locus that encodes the TMEM67/meckelin orphan receptor (Table 1). Subsequently, homozygosity mapping identified point mutations in CEP290 [73] and RPGRIP1L [46] as causes of MKS, as well as microdeletions in $C E P 290$ [74]. The identification of mutations in $C C 2 D 2 A$ for Finnish MKS families (excluded for mutations in $M K S 1$ ), provided an unusual example of a second major cause for a Finnish heritage disease [75]. In contrast, microheterogeneity at the MKS2 locus for two adjacent genes that both encode tetraspanin-like transmembrane proteins (TMEM138 and TMEM216), prevented the identification of mutations in TMEM216 as a cause of MKS until 2010 [53]. Interestingly, although mutations in TMEM216 are allelic for both JBTS and MKS, mutations in TMEM138 have not been described as a cause of MKS (Table 1). Conversely, MKS1 truncating mutations have only been described as a cause of MKS, and it remains highly likely that missense or hypomorphic mutations are a cause of JBTS.

Subsequent gene discovery studies for MKS have used WES to prioritize functional candidate genes, often based on sequence homology to known MKS or JBTS genes. For example, TCTN1, a known JBTS gene, was used to prioritize screening and then identify a pathogenic private mutation in TCTN2, a paralogue and member of the Tectonic family of genes [76]. Furthermore, the $M K S 1$ protein contains a B9 domain of unknown function that is also present in only two other proteins in the human genome (B9D1 and B9D2). Mutations in $B 9 D 1$ were identified as a cause of MKS [77], followed by the description of a family with a pathogenic private mutation in $B 9 D 2$ [78]. The most recently identified MKS genes include TMEM231 [79] and CSPP1 [66].

\section{Genotype-phenotype correlations}

JBTS and MKS both have unusually broad phenotypic variability, with many occasional clinical features that have been reported in addition to the obligate features. In principle, genotype-phenotype correlations would improve the prioritization of variants in diagnostic screens that use WES or targeted capture strategies. However, the correlations have proven to be broad and are difficult to apply in practice. In the next section, we provide an overview of the general genotype-phenotype correlations for JBTS and MKS, highlighting the most relevant for clinical practice and those that provide insights into protein function.

Marked genotype-phenotype correlations for JBTS include those for mutations in the NPHPI and AHII genes. These have an overall prevalence of $2 \%$ and $11 \%$ respectively, based on the screening of an unselected cohort of 117 JBTS patients [80], making AHII mutations a major cause of JBTS. JBTS caused by a deletion in NPHP 1 is associated with additional features that include nephronophthisis, with retinal and cerebellar involvement. However, the MTS was atypical in these patients and was characterized by moderate cerebellar vermis hypoplasia and elongated, but not thickened superior cerebellar peduncles [40, 81]. Patients with JBTS caused by AHII mutations have a high prevalence of retinal dystrophy, in the absence of occasional features such as polydactyly, liver fibrosis, coloboma or encephalocele. In one Dutch cohort, $75 \%$ of patients with AHI1 mutations had a retinal phenotype compared to $10 \%$ for a renal phenotype [82], although nephronophthisis and/or cortical polymicrogyria were also occasional features [83-85].

The most striking genotype-phenotype correlation is between TMEM67 mutations and the JBTS variant phenotype of COACH syndrome (Table 1). TMEM67 
mutations account for $57 \%$ to $83 \%$ [86-88] of cases of $\mathrm{COACH}$ syndrome, demonstrating the strongest association between TMEM67 mutations and liver involvement or coloboma [87, 89]. Due to this strong correlation, JBTS patients with liver involvement should be prioritized for TMEM67 screening [88]. Altogether mutations in TMEM67 have been found to account for $9 \%$ of JSRD patients, with or without liver disease [88]. Mutations in TMEM67 also cause $16 \%$ of all MKS cases [87], making TMEM67 mutations a major cause of MKS. Interestingly, both polydactyly and occipital encephalocele are less frequent in patients with TMEM67 mutations than those with $M K S 1$ mutations [90].

Several studies have identified correlations between the type of mutation, or location within a protein domain, with ciliopathy patient phenotype. For example, missense mutations in $C C 2 D 2 A$ have been associated with JBTS, whereas null alleles cause MKS [91]. Characteristic features of JBTS patients with $C C 2 D 2 A$ mutations include ventriculomegaly and seizures [92]. Another example is that missense mutations in exons 8 to 15 of TMEM67, especially in combination with a truncating mutation, are correlated with the MKS phenotype [87]. These exons encode the cysteine-rich domain of the TMEM67/meckelin orphan receptor, and missense mutations would presumably alter or prevent the binding of the uncharacterized ligands to this receptor.
Similarly, mutations in AHII appear to cluster in the predicted WD40 domain of the jouberin/AHI1 protein $[80,83]$ which is thought to mediate protein-protein interactions. Clustering of RPGRIPIL missense mutations (including p.T516P, the most common missense mutation) also occurs in exon 15 for patients with JBTS and renal involvement $[93,94]$. RPGRIPIL exon 15 encodes a $\mathrm{C} 2$ protein domain in this protein, which is a calcium-dependent membrane-targeting region that binds to phospholipids and inositol polyphosphates. C2 protein domains are exclusively found in signal transduction enzymes such as protein kinase $\mathrm{C}$ or membrane trafficking proteins. Interestingly, CC2D2A also contains a $\mathrm{C} 2$ domain, and these findings clearly implicate the JBTS and MKS ciliary proteins in the transduction and regulation of multiple signaling pathways during embryonic development.

\section{Insights into molecular mechanisms from gene discovery studies}

Following the initial gene discovery studies, contemporary research has focused on the delineation of possible cellular functions for JBTS and MKS ciliary proteins. Several recent studies have used biochemical assays and proteomic studies to delineate networks of protein-protein interactions (Fig. 2) and in some instances infer possible functions from those of other better characterized members of a complex.

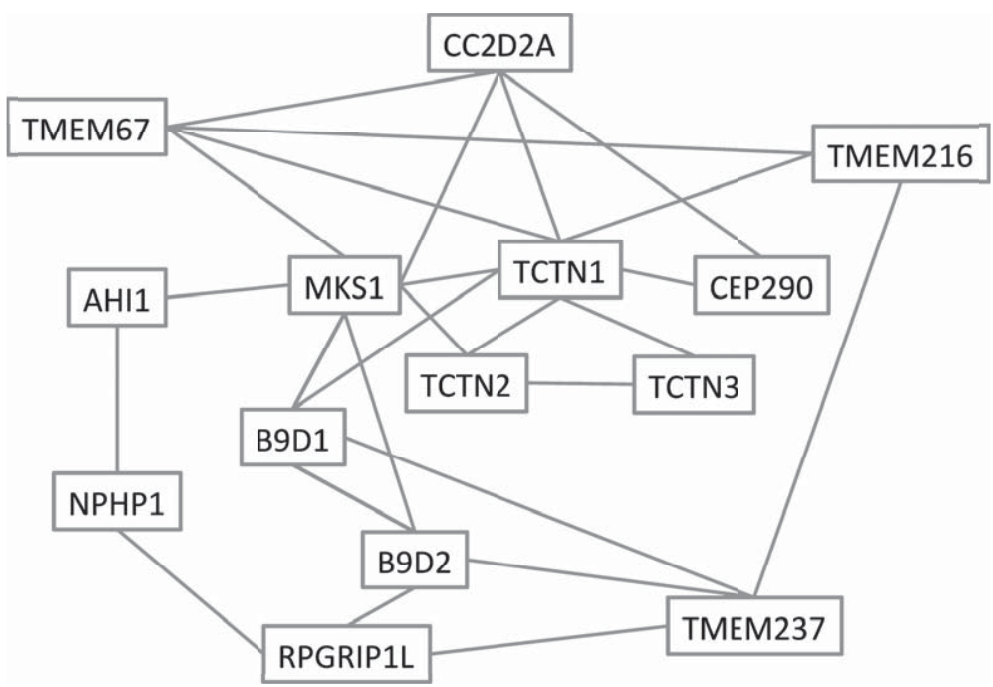

Fig. 2. Schematic representation of experimentally verified Joubert syndrome (JBTS) and Meckel-Gruber syndrome (MKS) protein-protein interactions. The network summarizes the interactions (gray lines) that form the "MKS-JBTS module" at the ciliary transition zone. Protein names are indicated in black boxes. Biochemical methods to determine interactions included yeast two-hybrid assays and proteomics studies. See main text for further details. 
Elegant transgenesis and localization studies in animal models such as zebrafish (Danio rerio) and the nematode Caenorhabditis elegans have inferred genetic interactions between JBTS and MKS genes, although these do not always support the existence of biochemical interactions. However, in most of these studies the target ciliary protein is over-expressed either with a convenient epitope tag for biochemical purification, or a fluorescent protein reporter in genetic interaction experiments, and is not at physiological levels of expression. It remains problematic if over-expressed proteins correctly model the localization and interactions of the in vivo cognate protein, and these studies should be interpreted with some caution.

Despite these limitations, several studies have identified the protein complex known as the "MKS-JBTS module" at the ciliary TZ that contains many JBTS and MKS proteins [6, 7]. These include all of the known small tetraspanin-like TMEMs mutated in ciliopathies (TMEM216, TMEM138, TMEM237 and TMEM231), as well as others (TMEM17 and TMEM107) that have yet to be implicated in a human ciliopathy. The Tectonic transmembrane proteins (TCTN1, TCTN2 and TCTN3) and the orphan receptor TMEM67/meckelin also localize to the TZ. All of these transmembrane proteins are thought to be inserted into the local plasma membrane at the TZ. This, in turn, may mediate interactions or regulate the function of membrane-targeting proteins with $\mathrm{C} 2$ domains such as RPGRIP1L and CC2D2A [6, 7]. For example, a proteomics study of TCTN1 showed that this protein forms a complex at the TZ with MKS1, TMEM216, TMEM67, CEP290, B9D1, TCTN2 and CC2D2A [55] (Fig. 2). Confirmation of the direct interaction between CC2D2A and CEP290 has come from yeast two-hybrid studies and glutathionine S-transferase (GST) pull-downs, with genetic interactions between these genes also demonstrated in zebrafish models [48].

The role of CEP290 and the B9 proteins at the TZ remains unclear, but they presumably act as linkers or mediators between the TMEMs and either the vesicular cargo that is targeted to the TZ during ciliogenesis, or the subsequent transport of cargo proteins within the cilium by IFT. The former model is supported by analogy from studies on AHI1/jouberin, a JBTS ciliary protein that contains WD40 and Src Homology 3 (SH3) protein interaction domains. AHI1/jouberin interacts with RAB8A, a small GTP/GDP-binding protein that mediates the vesicular transport of proteins from the endoplasmic reticulum to the Golgi and the plasma membrane [95]. Loss of AHI1/jouberin causes defects in ciliogenesis and also defects in vesicle transport [95].

The elaborate machinery of the TZ appears to be in place to maintain the integrity of the ciliary gate, and the disruption of this function may contribute to the ciliopathy phenotype by altering the composition of the ciliary membrane or axoneme [96]. Several recent studies have confirmed that disruption of the $\mathrm{TZ}$ results in the incorrect movement of proteins in and out of the cilium, with particular emphasis on the transport of enzymes and transmembrane proteins that mediate intracellular signaling. For example, TMEM231 and TMEM17 localize to the TZ, with the localization of TMEM231 dependent on other TZ proteins (CC2D2A and B9D1) [97]. In turn, this regulated the transport of G-protein-coupled signaling receptors (GPCRs; specifically, somatostatin and serotonin receptors SSTR3 and HTR6) into the ciliary membrane [97]. Loss of either Tmem 231 or B9d2 in mice caused defects in ciliogenesis and Shh signaling [97]. Sang et al. [68] showed that loss of Tctn2 caused defects in ciliogenesis. In a separate study, loss of Tctn1, Tctn2, Tmem67 or Cc2d2a caused tissue-specific defects in ciliogenesis and ciliary membrane composition. In addition, defects were observed in the ciliary localization of adenylyl cyclase 3 (ACIII, an enzyme that catalyzes the formation of the secondary messenger cAMP), the transmembrane signaling proteins smoothened and Pkd2/polycystin-2, and Arl13b (a small Arf-family GTPase) [55]. Interestingly, Arl13b regulates the migration of interneurons in the developing brain, and this may provide a partial explanation for the neurological defects observed in JBTS patients [98].

In contrast to other JBTS and MKS proteins that predominantly localize to the ciliary TZ, both ARL13B and INPP5E localize to the ciliary axoneme. The ciliary localization of ARL13B depends on TZ function, as described above, but the axonemal localization of INPP5E depends on the functions of both ARL13B and PDE6D (a phosphodiesterase that appears to act as a chaperone for prenylated ciliary and retinal proteins) $[55,64,99]$. An attractive hypothesis is that INPP5E dysfunction (due to either mutation or mislocalization) causes alterations in ciliary signaling through changes in the levels of the secondary messenger InsP3. It is probable that this is one of the fundamental pathogenic mechanisms in both JBTS and MKS, but it has yet to be formally tested. The JBTS phenotype has also 
been associated with alterations in the tubulin posttranslational modifications of the ciliary axoneme, and this would presumably affect both the stability of the cilium and the trafficking of ciliary proteins. Specifically, the JBTS protein CEP41, encoding a centrosomal and microtubule-binding protein, regulates the entry of TTLL6 (a tubulin polyglutamylase enzyme) to the ciliary axoneme [57]. This thus implicates tubulin post-translational modification and therefore the composition of the axoneme in the ciliopathy phenotype $[57,100]$.

Finally, the loss or mislocalization of many JBTS and MKS proteins cause defects in Shh signaling, as demonstrated in a number of mouse ciliopathy models [97, 101-103]. One explanation is that TZ disruption prevents the correct trafficking of KIF7, a ciliaryassociated kinesin motor protein that regulates Shh signaling through altering the relative levels of the activator and repressor isoforms of GLI transcription factors [54, 104]. GLI proteins are the downstream effectors of the Shh signaling pathway, and KIF7 appears to act as both a negative regulator by preventing the inappropriate activation of GLI2 in the absence of ligand, and as a positive regulator by preventing the processing of GLI3 into its repressor form. Animal models with loss of TZ-associated JBTS and MKS proteins also have dysregulation of the "canonical" and "non-canonical" branches of the Wnt signaling pathway [53, 101, 103, 105, 106], but the mechanistic detail of how the ciliary TZ regulates this pathway is less clear than for the Shh pathway. One possibility, at least for the canonical $\beta$-catenin-mediated branch, is that $\mathrm{AHI} / \mathrm{jouberin}$ directly interacts and sequestrates the downstream effector $\beta$-catenin at the cilium $[107,108]$. In turn, this would limit the nuclear entry of $\beta$-catenin and its availability to act as a transcription factor for Wnt-responsive genes.

\section{Future perspectives}

To date, mutations in the known JBTS and MKS genes appear to account for no more than $60 \%$ cases. The spectrum of causative genes for these conditions is therefore incomplete, but the remaining genes are likely to be uncommon or even harbor mutations that are private to a single family. However, with the widespread availability and affordability of WES and targeted clonal sequencing techniques such as molecular inversion probe sequencing, many researchers are re-investigating known genes in patients that have been previously mutation negative. In addition, wholegenome sequencing (WGS) at low coverage depth now allows rapid copy number analysis. These studies are likely to uncover copy number variations and intronic mutations, as well as changes in the promoter sequence or in cis regulatory elements as potential pathogenic causes. This will improve JBTS and MKS patient diagnosis, and with the emerging genotype-phenotype correlations for JBTS variants such as $\mathrm{COACH}$, prognostic testing may be improved as well. However, as described above, the efforts to describe most of these correlations in anything but broad terms are confounded by both the allelism and unusual phenotypic variability for these conditions. Furthermore, the range of phenotypes associated with the ciliopathies continues to be broadened [109-114]. The molecular mechanisms that cause such phenotypic variability remain largely unknown, but are likely to include the effect of modifier alleles in other ciliary-related genes and stochastic effects in signaling pathways during embryonic development. Two examples that support the former hypothesis include the association of common missense coding variants in the RPGRIPIL and AHIl genes with the expressivity of retinal degeneration in the ciliopathy phenotype. Thr229 in the common variant p.A229T in RPGRIPIL is associated with retinal degeneration in a range of ciliopathies including JBTS and MKS [115], and Trp830 in the variant p.R830W in AHI1/jouberin is associated with a more than sevenfold increase in relative risk of retinal degeneration within a cohort of individuals with the kidney ciliopathy nephronophthisis [116].

These findings and recent developments in WES and WGS emphasize the difficulties in assessing the pathogenic potential of variants of unknown significance in both basic research and clinical diagnosis of not only the ciliopathies but, more generally, for AR conditions [117]. This is a key challenge that needs to be addressed to prevent false positive results from hindering the translation of research findings into clinical diagnostic testing and to enable the further biological understanding of disease mechanisms. For JBST and MKS, the major causative genes are now known and there are good insights into the function for some of the encoded proteins. In interpreting variants of unknown significance in the ciliopathies, researchers and clinical scientists can now take full advantage of public datasets of genomic variation, functional genomic data and model-organism phenotypes. However, it remains important that variants identified from the many 
targeted screening and WES experiments for JBTS and MKS are reported as public datasets with a standard nomenclature that follows published guidelines. For this purpose, we would suggest that the Leiden Open Variation Database v3.0 is used since this provides both gene- and patient-specific data storage, including datasets from WES and WGS [118].

In the near future, we envisage the further convergence of genetic data with other independent lines of evidence that assess the pathogenic potential of a variant. These will include comparative genomic approaches and bioinformatic datasets, although the experimental validation of the damaging impact of a candidate variant still provides the most definitive proof. Future studies should use assays of patientderived cells or tissues, as well as well-established cell or animal models of gene function. Not only will these lead to improvements in the diagnosis and clinical management of ciliopathy patients, but they will also provide pre-clinical models to test future therapeutic interventions. In JBTS, these could modify or treat cystic kidney disease or ciliopathy disease progression, and perhaps the long-term outlook of patients with these conditions. Since JBTS and MKS are predominantly AR, they are caused by the absence of normal protein (rather than the presence of an abnormal protein) so they can, in principle, be corrected by gene-replacement. In the first demonstration of this strategy in a ciliopathy mouse model, McIntyre et al. [119] used the well-established Ift $88^{T g 737 R p w}$ mouse mutant with many typical phenotypic features including anosmia. Remarkably, the adenoviral-mediated expression of Ift88 (a protein essential for IFT in cilia) in fully-differentiated olfactory sensory neurons of mutant mice was sufficient to restore both ciliary structures and rescue olfactory function [119]. In the future, targeted therapies such as antisense oligonucleotide therapy and stop codon read-through therapy may be beneficial for patients with suitable splice-site or nonsense mutations. This makes the JBTS and MKS group of ciliopathies a top priority for further genetic and functional characterization in order to prioritize patients for these potential treatments.

\section{Acknowledgments}

We thank Dr. Daniel Doherty (Seattle Children's Hospital, University of Washington, USA) and Dr. Riitta Salonen (Rinnekoti Foundation, Helsinki,
Finland) for their permission to use clinical images. This work was supported by funding from the Medical Research Council, grant number MR/K011154/1 and the European Community's Seventh Framework Programme FP7/2009 under grant agreement no. 241955 SYSCILIA.

\section{References}

[1] Goetz SC, Anderson KV. The primary cilium: A signalling centre during vertebrate development. Nat Rev Genet 2010;11(5):331-44

[2] Adams M, Smith UM, Logan CV, Johnson CA. Recent advances in the molecular pathology, cell biology and genetics of ciliopathies. J Med Genet 2008;45(5):257-67.

[3] Quinlan RJ, Tobin JL, Beales PL. Modeling ciliopathies Primary cilia in development and disease. Curr Top Dev Biol 2008;84:249-310.

[4] Szymanska K, Johnson CA. The transition zone: An essential functional compartment of cilia. Cilia 2012;1(1): 10

[5] Reiter JF, Blacque OE, Leroux MR. The base of the cilium: Roles for transition fibres and the transition zone in ciliary formation, maintenance and compartmentalization. EMBO Rep 2012;13(7):608-18.

[6] Garcia-Gonzalo FR, Reiter JF. Scoring a backstage pass: Mechanisms of ciliogenesis and ciliary access. J Cell Biol 2012;197(6):697-709.

[7] Blacque OE, Sanders AA. Compartments within a compartment: What C. elegans can tell us about ciliary subdomain composition, biogenesis, function, and disease. Organogenesis $2014 ; 10(1): 126-37$

[8] Parisi MA. Clinical and molecular features of Joubert syndrome and related disorders. Am J Med Genet C Semin Med Genet 2009;151C(4):326-40.

[9] Joubert M, Eisenring JJ, Robb JP, Andermann F. Familial agenesis of the cerebellar vermis. A syndrome of episodic hyperpnea, abnormal eye movements, ataxia, and retardation. Neurology 1969;19(9):813-25.

[10] Maria BL, Boltshauser E, Palmer SC, Tran TX. Clinica features and revised diagnostic criteria in Joubert syndrome. J Child Neurol 1999;14(9):583-90.

[11] Saraiva JM, Baraitser M. Joubert syndrome: A review. Am J Med Genet 1992;43(4):726-31.

[12] Parisi MA, Doherty D, Chance PF, Glass IA. Joubert syndrome (and related disorders) (OMIM 213300). Eur J Hum Genet 2007;15(5):511-21.

[13] Maria BL, Quisling RG, Rosainz LC, Yachnis AT, Gitten J, Dede D, et al. Molar tooth sign in Joubert syndrome: Clinical, radiologic, and pathologic significance. J Child Neurol 1999;14(6):368-76.

[14] Maria BL, Bozorgmanesh A, Kimmel KN, Theriaque D Quisling RG. Quantitative assessment of brainstem development in Joubert syndrome and Dandy-Walker syndrome. J Child Neurol 2001;16(10):751-8.

[15] Valente EM, Salpietro DC, Brancati F, Bertini E, Galluccio T, Tortorella G, et al. Description, nomenclature, and mapping of a novel cerebello-renal syndrome with the molar tooth malformation. Am J Hum Genet 2003;73(3): 663-70. 
[16] Satran D, Pierpont ME, Dobyns WB. Cerebello-oculo-renal syndromes including Arima, Senior-Löken and $\mathrm{COACH}$ syndromes: More than just variants of Joubert syndrome. Am J Med Genet 1999;86(5):459-69.

[17] Romani M, Micalizzi A, Valente EM. Joubert syndrome: Congenital cerebellar ataxia with the molar tooth. Lancet Neurol 2013;12(9):894-905.

[18] Parisi M, Glass I. Joubert Syndrome and Related Disorders. In: Pagon RA, Adam MP, Ardinger HH, Bird TD, Dolan CR, Fong CT, Smith RJH, Stephens $\mathrm{K}$, editors. GeneReviews. Available at: http://www. ncbi.nlm.nih.gov/books/NBK1325/. Seattle WA: University of Washington, Seattle; 1993-2014. Accessed May, 2014

[19] Salonen R, Paavola P. Meckel syndrome. J Med Genet 1998;35(6):497-501.

[20] Chen CP. Meckel syndrome: Genetics, perinatal findings, and differential diagnosis. Taiwan J Obstet Gynecol 2007;46(1):9-14

[21] Ahdab-Barmada M, Claassen D. A distinctive triad of malformations of the central nervous system in the Meckel-Gruber syndrome. J Neuropath Exp Neurol 1990;49(6):610-20

[22] Salonen R. The Meckel syndrome: Clinicopathological findings in 67 patients. Am J Med Genet 1984;18(4):671-89.

[23] Blankenberg TA, Ruebner BH, Ellis WG, Bernstein J, Dimmick JE. Pathology of renal and hepatic anomalies in Meckel syndrome. J Med Genet Suppl 1987;3:395-410.

[24] Sergi C, Adam S, Kahl P, Otto HF. Study of the malformation of ductal plate of the liver in Meckel syndrome and review of other syndromes presenting with this anomaly. Pediatr Dev Pathol 2000;3(6):568-583.

[25] Lowry RB, Hill RH, Tischler B. Survival and spectrum of anomalies in the Meckel syndrome. Am J Med Genet 1983;14(3):417-21

[26] Moerman P, Verbeken E, Fryns JP, Goddeeris P, Lauweryns JM. The Meckel syndrome. Pathological and cytogenetic observations in eight cases. Hum Genet 1982;62(3):240-5.

[27] Seppanen U, Herva R. Roentgenologic features of the Meckel syndrome. Pediatr Radiol 1983;13(6):329-31.

[28] Rapola J, Salonen R. Visceral anomalies in the Meckel syndrome. Teratology 1985;31(2):193-201.

[29] Paavola P, Salonen R, Weissenbach J, Peltonen L. The locus for Meckel syndrome with multiple congenital anomalies maps to chromosome 17q21-q24. Nat Genet 1995;11(2):213-5.

[30] Sepulveda W, Sebire NJ, Souka A, Snijders RJ, Nicolaides KH. Diagnosis of the Meckel-Gruber syndrome at eleven to fourteen weeks' gestation. Am J Obstet Gynecol 1997; 176(2):316-9

[31] Tongsong T, Piyamongkol W, Pongsatha S. Prenatal diagnosis of Meckel syndrome: A case report. J Obstet Gynaecol Res 1999;25(5):339-42.

[32] Ramadani HM, Nasrat HA. Prenatal diagnosis of recurrent Meckel syndrome. Int J Gynaecol Obstet 1992;39(4):32732.

[33] Eckmann-Scholz C, Jonat W, Zerres K, Ortiz-Brüchle N. Earliest ultrasound findings and description of splicing mutations in Meckel-Gruber syndrome. Arch Gynecol Obstet 2012;286(4):917-21.

[34] Boltshauser E, Isler W. Joubert syndrome: Episodic hyperpnea, abnormal eye movements, retardation and ataxia, associated with dysplasia of the cerebellar vermis. Neuropadiatrie $1977 ; 8(1): 57-66$.
[35] Natacci F, Corrado L, Pierri M, Rossetti M, Zuccarini C, Riva P, et al. Patient with large 17p11.2 deletion presenting with Smith-Magenis syndrome and Joubert syndrome phenotype. Am J Med Genet 2000;95(5):467-72

[36] Saar K, Al-Gazali L, Sztriha L, Rueschendorf F, Nur-EKamal M, Reis A, et al. Homozygosity mapping in families with Joubert syndrome identifies a locus on chromosome $9 \mathrm{q} 34.3$ and evidence for genetic heterogeneity. Am J Hum Genet 1999;65(6):1666-71.

[37] Lagier-Tourenne C, Boltshauser E, Breivik N, Gribaa M, Bétard C, Barbot C, et al. Homozygosity mapping of a third Joubert syndrome locus to 6q23. J Med Genet 2004;41(4): 273-7.

[38] Bennett CL, Parisi MA, Eckert ML, Huynh HM, Chance PF, Glass IA. Joubert syndrome: A haplotype segregation strategy and exclusion of the zinc finger protein of cerebellum 1 (ZIC1) gene. Am J Med Genet A 2004;125A(2):117-24.

[39] Keeler LC, Marsh SE, Leeflang EP, Woods CG, Sztriha L, Al-Gazali L, et al. Linkage analysis in families with Joubert syndrome plus oculo-renal involvement identifies the CORS2 locus on chromosome 11p12-q13.3. Am J Hum Genet 2003;73(3):656-62.

[40] Parisi MA, Bennett CL, Eckert ML, Dobyns WB, Gleeson JG, Shaw DW, et al. The NPHP1 gene deletion associated with juvenile nephronophthisis is present in a subset of individuals with Joubert syndrome. Am J Hum Genet 2004;75(1):82-91.

[41] Ferland RJ, Eyaid W, Collura RV, Tully LD, Hill RS, AlNouri D, et al. Abnormal cerebellar development and axonal decussation due to mutations in AHI1 in Joubert syndrome Nat Genet 2004;36(9):1008-13.

[42] Valente EM, Silhavy JL, Brancati F, Barrano G, Krishnaswami SR, Castori M, et al. Mutations in CEP290, which encodes a centrosomal protein, cause pleiotropic forms of Joubert syndrome. Nat Genet 2006;38(6):623-5.

[43] Sayer JA, Otto EA, O'Toole JF, Nurnberg G, Kennedy MA, Becker C, et al. The centrosomal protein nephrocystin-6 is mutated in Joubert syndrome and activates transcription factor ATF4. Nat Genet 2006;38(6):674-81.

[44] Baala L, Romano S, Khaddour R, Saunier S, Smith UM, Audollent S, et al. The Meckel-Gruber syndrome gene, MKS3, is mutated in Joubert syndrome. Am J Hum Genet 2007;80(1):186-94

[45] Arts HH, Doherty D, van Beersum SE, Parisi MA, Letteboer SJ, Gorden NT, et al. Mutations in the gene encoding the basal body protein RPGRIP1L, a nephrocystin-4 interactor, cause Joubert syndrome. Nat Genet 2007;39(7):882-8.

[46] Delous M, Baala L, Salomon R, Laclef C, Vierkotten J, Tory $\mathrm{K}$, et al. The ciliary gene RPGRIP1L is mutated in cerebello-oculo-renal syndrome (Joubert syndrome type B) and Meckel syndrome. Nat Genet 2007;39(7):875-81.

[47] Cantagrel V, Silhavy JL, Bielas SL, Swistun D, Marsh SE, Bertrand JY, et al. Mutations in the cilia gene ARL13B lead to the classical form of Joubert syndrome. Am J Hum Genet 2008;83(2):170-9

[48] Gorden NT, Arts HH, Parisi MA, Coene KL, Letteboer $\mathrm{SJ}$, van Beersum SE, et al. CC2D2A is mutated in Joubert syndrome and interacts with the ciliopathy-associated basal body protein CEP290. Am J Hum Genet 2008;83(5):559-71

[49] Bielas SL, Silhavy JL, Brancati F, Kisseleva MV, Al-Gazali L, Sztriha L, et al. Mutations in INPP5E, encoding inositol polyphosphate-5-phosphatase E, link phosphatidyl inositol signaling to the ciliopathies. Nat Genet 2009;41(9):1032-6. 
[50] Kroes HY, Nievelstein RJ, Barth PG, Nikkels PG, Bergmann C, Gooskens RH, et al. Cerebral, cerebellar, and colobomatous anomalies in three related males: Sex-linked inheritance in a newly recognized syndrome with features overlapping with Joubert syndrome. Am J Med Genet A 2005;135(3):297-301.

[51] Coene KL, Roepman R, Doherty D, Afroze B, Kroes HY, Letteboer SJ, et al. OFD1 is mutated in X-linked Joubert syndrome and interacts with LCA5-encoded lebercilin. Am J Hum Genet 2009;85(4):465-81.

[52] Edvardson S, Shaag A, Zenvirt S, Erlich Y, Hannon GJ, Shanske AL, et al. Joubert syndrome 2 (JBTS2) in Ashkenazi Jews is associated with a TMEM216 mutation. Am J Hum Genet 2010;86(1):93-7.

[53] Valente EM, Logan CV, Mougou-Zerelli S, Lee JH, Silhavy JL, Brancati F, et al. Mutations in TMEM216 perturb ciliogenesis and cause Joubert, Meckel and related syndromes. Nat Genet 2010;42(7):619-25.

[54] Dafinger C, Liebau MC, Elsayed SM, Hellenbroich Y, Boltshauser E, Korenke GC, et al. Mutations in KIF7 link Joubert syndrome with Sonic Hedgehog signaling and microtubule dynamics. J Clin Invest 2011;121(7):2662-7.

[55] Garcia-Gonzalo FR, Corbit KC, Sirerol-Piquer MS, Ramaswami G, Otto EA, Noriega TR, et al. A transition zone complex regulates mammalian ciliogenesis and ciliary membrane composition. Nat Genet 2011;43(8):776-84.

[56] Alazami AM, Alshammari MJ, Salih MA, Alzahrani F, Hijazi H, Seidahmed MZ, et al. Molecular characterization of Joubert syndrome in Saudi Arabia. Hum Mutat 2012;33(10):1423-8.

[57] Lee JE, Silhavy JL, Zaki MS, Schroth J, Bielas SL, Marsh SE, et al. CEP41 is mutated in Joubert syndrome and is required for tubulin glutamylation at the cilium. Nat Genet 2012;44(2):193-9.

[58] Lee JH, Silhavy JL, Lee JE, Al-Gazali L, Thomas S, Davis EE, et al. Evolutionarily assembled cis-regulatory module at a human ciliopathy locus. Science 2012;335(6071):966-9.

[59] Huang L, Szymanska K, Jensen VL, Janecke AR, Innes AM, Davis EE, et al. TMEM237 is mutated in individuals with a Joubert syndrome related disorder and expands the role of the TMEM family at the ciliary transition zone. Am J Hum Genet 2011;89(6):713-30.

[60] Srour M, Schwartzentruber J, Hamdan FF, Ospina LH, Patry L, Labuda D, et al. Mutations in C5ORF42 cause Joubert syndrome in the French Canadian population. Am J Hum Genet 2012;90(4):693-700.

[61] Dixon-Salazar TJ, Silhavy JL, Udpa N, Schroth J, Bielas $\mathrm{S}$, Schaffer AE, et al. Exome sequencing can improve diagnosis and alter patient management. Sci Transl Med 2012;4(138):138ra78.

[62] Thomas S, Legendre M, Saunier S, Bessieres B, Alby C, Bonniere M, et al. TCTN3 mutations cause Mohr-Majewski syndrome. Am J Hum Genet 2012;91(2):372-8.

[63] Srour M, Hamdan FF, Schwartzentruber JA, Patry L, Ospina LH, Shevell MI, et al. Mutations in TMEM231 cause Joubert syndrome in French Canadians. J Med Genet 2012;49(10):636-41.

[64] Thomas S, Wright KJ, Le Corre S, Micalizzi A, Romani M, Abhyankar A, et al. A homozygous PDE6D mutation in Joubert syndrome impairs targeting of farnesylated INPP5E protein to the primary cilium. Hum Mutat 2014;35(1): 137-46.
[65] Akizu N, Silhavy JL, Rosti RO, Scott E, Fenstermaker AG Schroth J, et al. Mutations in CSPP1 lead to classical Joubert syndrome. Am J Hum Genet 2014;94(1):80-6.

[66] Shaheen R, Shamseldin HE, Loucks CM, Seidahmed MZ, Ansari S, Ibrahim KM, et al. Mutations in CSPP1, encoding a core centrosomal protein, cause a range of ciliopathy phenotypes in humans. Am J Hum Genet 2014;94(1): 73-9.

[67] Tuz K, Bachmann-Gagescu R, O’Day DR, Hua K, Isabella $\mathrm{CR}$, Phelps IG, et al. Mutations in CSPP1 cause primary cilia abnormalities and Joubert syndrome with or without Jeune asphyxiating thoracic dystrophy. Am J Hum Genet 2014;94(1):62-72.

[68] Sang L, Miller JJ, Corbit KC, Giles RH, Brauer MJ, Otto EA, et al. Mapping the NPHP-JBTS-MKS protein network reveals ciliopathy disease genes and pathways. Cell 2011;145(4):513-28.

[69] Roume J, Genin E, Cormier-Daire V, Ma HW, Mehaye B, Attie T, et al. A gene for Meckel syndrome maps to chromosome 11q13. Am J Hum Genet 1998;63(4):1095-101.

[70] Morgan NV, Gissen P, Sharif SM, Baumber L, Sutherland J, Kelly DA, et al. A novel locus for Meckel-Gruber syndrome, MKS3, maps to chromosome 8q24. Hum Genet 2002;111(45):456-61.

[71] Kyttälä M, Tallila J, Salonen R, Kopra O, Kohlschmidt N, Paavola-Sakki P, et al. MKS1, encoding a component of the flagellar apparatus basal body proteome, is mutated in Meckel syndrome. Nat Genet 2006;38(2):155-7.

[72] Smith UM, Consugar M, Tee LJ, McKee BM, Maina EN, Whelan S, et al. The transmembrane protein meckelin (MKS3) is mutated in Meckel-Gruber syndrome and the wpk rat. Nat Genet 2006;38(2):191-6.

[73] Baala L, Audollent S, Martinovic J, Ozilou C, Babron MC, Sivanandamoorthy S, et al. Pleiotropic effects of CEP290 (NPHP6) mutations extend to Meckel syndrome. Am J Hum Genet 2007;81(1):170-9.

[74] Molin A, Benoist G, Jeanne-Pasquier C, Elkartoufi N, Litzer J, Decamp M, et al. 12q21 Microdeletion in a fetus with Meckel syndrome involving CEP290/MKS4. Eur J Med Genet 2013;56(10):580-3

[75] Tallila J, Jakkula E, Peltonen L, Salonen R, Kestila M. Identification of CC2D2A as a Meckel syndrome gene adds an important piece to the ciliopathy puzzle. Am J Hum Genet 2008;82(6):1361-7

[76] Shaheen R, Faqeih E, Seidahmed MZ, Sunker A, Alal FE, AlQahtani K, et al. A TCTN2 mutation defines a novel Meckel Gruber syndrome locus. Hum Mutat 2011;32(6):573-8.

[77] Hopp K, Heyer CM, Hommerding CJ, Henke SA, Sundsbak JL, Patel S, et al. B9D1 is revealed as a novel Meckel syndrome (MKS) gene by targeted exon-enriched nextgeneration sequencing and deletion analysis. Hum Mol Genet 2011;20(13):2524-34.

[78] Dowdle WE, Robinson JF, Kneist A, Sirerol-Piquer MS, Frints SG, Corbit KC, et al. Disruption of a ciliary B9 protein complex causes Meckel syndrome Am J Hum Genet 2011;89(1):94-110.

[79] Shaheen R, Ansari S, Mardawi EA, Alshammari MJ, Alkuraya FS. Mutations in TMEM231 cause Meckel-Gruber syndrome. J Med Genet 2013;50(3):160-2.

[80] Parisi MA, Doherty D, Eckert ML, Shaw DW, Ozyurek H, Aysun S, et al. AHI1 mutations cause both retinal dystrophy 
and renal cystic disease in Joubert syndrome. J Med Genet 2006;43(4):334-9.

[81] Castori M, Valente EM, Donati MA, Salvi S, Fazzi E, Procopio E, et al. NPHP1 gene deletion is a rare cause of Joubert syndrome related disorders. J Med Genet 2005;42(2):e9.

[82] Kroes HY, van Zon PH, Fransen van de Putte D, Nelen MR, Nievelstein RJ, Wittebol-Post D, et al. DNA analysis of AHI1, NPHP1 and CYCLIN D1 in Joubert syndrome patients from the Netherlands. Eur J Med Genet 2008;51(1):24-34.

[83] Dixon-Salazar T, Silhavy JL, Marsh SE, Louie CM, Scott LC, Gururaj A, et al. Mutations in the AHI1 gene, encoding jouberin, cause Joubert syndrome with cortical polymicrogyria. Am J Hum Genet 2004;75(6):979-87.

[84] Giordano L, Vignoli A, Pinelli L, Brancati F, Accorsi P, Faravelli F, et al. Joubert syndrome with bilateral polymicrogyria: Clinical and neuropathological findings in two brothers. Am J Med Genet Part A 2009;149A(7):1511-5.

[85] Utsch B, Sayer JA, Attanasio M, Pereira RR, Eccles M, Hennies $\mathrm{HC}$, et al. Identification of the first AHI1 gene mutations in nephronophthisis-associated Joubert syndrome. Pediatr Nephrol 2006;21(1):32-5.

[86] Brancati F, Iannicelli M, Travaglini L, Mazzotta A, Bertini E, Boltshauser E, et al. MKS3/TMEM67 mutations are a major cause of $\mathrm{COACH}$ Syndrome, a Joubert syndrome related disorder with liver involvement. Hum Mutat 2009;30(2):E432-42

[87] Iannicelli M, Brancati F, Mougou-Zerelli S, Mazzotta A, Thomas S, Elkhartoufi N, et al. Novel TMEM67 mutations and genotype-phenotype correlates in meckelin-related ciliopathies. Hum Mutat 2010;31(5):E1319-31.

[88] Doherty D, Parisi MA, Finn LS, Gunay-Aygun M, AlMateen M, Bates D, et al. Mutations in 3 genes (MKS3, CC2D2A and RPGRIP1L) cause COACH syndrome (Joubert syndrome with congenital hepatic fibrosis). J Med Genet 2010;47(1):8-21.

[89] Otto EA, Tory K, Attanasio M, Zhou W, Chaki M, Paruchuri Y, et al. Hypomorphic mutations in meckelin (MKS3/TMEM67) cause nephronophthisis with liver fibrosis (NPHP11). J Med Genet 2009;46(10):663-70.

[90] Khaddour R, Smith U, Baala L, Martinovic J, Clavering D, Shaffiq R, et al. Spectrum of MKS1 and MKS3 mutations in Meckel syndrome: A genotype-phenotype correlation. Mutation in brief \#960. Online. Hum Mutat 2007;28(5): 523-4.

[91] Mougou-Zerelli S, Thomas S, Szenker E, Audollent S, Elkhartoufi N, Babarit C, et al. CC2D2A mutations in Meckel and Joubert syndromes indicate a genotypephenotype correlation. Hum Mutat 2009;30(11):1574-82.

[92] Bachmann-Gagescu R, Ishak GE, Dempsey JC, Adkins J, O'Day D, Phelps IG, et al. Genotype-phenotype correlation in CC2D2A-related Joubert syndrome reveals an association with ventriculomegaly and seizures. J Med Genet 2012;49(2):126-37.

[93] Wolf MT, Saunier S, O'Toole JF, Wanner N, Groshong T, Attanasio M, et al. Mutational analysis of the RPGRIP1L gene in patients with Joubert syndrome and nephronophthisis. Kidney Int 2007;72(12):1520-6

[94] Brancati F, Travaglini L, Zablocka D, Boltshauser E, Accorsi P, Montagna G, et al. RPGRIP1L mutations are mainly associated with the cerebello-renal phenotype of Joubert syndrome-related disorders. Clin Genet 2008;74(2): 164-70.
[95] Hsiao YC, Tong ZJ, Westfall JE, Ault JG, Page-McCaw PS, Ferland RJ. AHI1, whose human ortholog is mutated in Joubert syndrome, is required for Rab8a localization, ciliogenesis and vesicle trafficking. Hum Mol Genet 2009;18(20):3926-41.

[96] Williams CL, Li C, Kida K, Inglis PN, Mohan S, Semenec L, et al. MKS and NPHP modules cooperate to establish basal body/transition zone membrane associations and ciliary gate function during ciliogenesis. J Cell Biol 2011;192(6): 1023-41.

[97] Chih B, Liu P, Chinn Y, Chalouni C, Komuves LG, Hass PE, et al. A ciliopathy complex at the transition zone protects the cilia as a privileged membrane domain. Nat Cell Biol 2011;14(1):61-72

[98] Higginbotham H, Eom TY, Mariani LE, Bachleda A, Hirt $\mathrm{J}$, Gukassyan V, et al. Arl13b in primary cilia regulates the migration and placement of interneurons in the developing cerebral cortex. Dev Cell 2012;23(5):925-38

[99] Humbert MC, Weihbrecht K, Searby CC, Li Y, Pope RM, Sheffield VC, et al. ARL13B, PDE6D, and CEP164 form a functional network for INPP5E ciliary targeting. Proc Natl Acad Sci U S A 2012;109(48):19691-6.

[100] Sergouniotis PI, Chakarova C, Murphy C, Becker M, Lenassi E, Arno G, et al. Biallelic variants in TTLL5, encoding a tubulin glutamylase, cause retinal dystrophy. Am J Hum Genet 2014;94(5):760-9.

[101] Cui C, Chatterjee B, Francis D, Yu Q, SanAgustin JT, Francis $\mathrm{R}$, et al. Disruption of Mks1 localization to the mother centriole causes cilia defects and developmental malformations in Meckel-Gruber syndrome. Dis Model Mech 2011;4(1): 43-56.

[102] Weatherbee SD, Niswander LA, Anderson KV. A mouse model for Meckel syndrome reveals Mks1 is required for ciliogenesis and Hedgehog signaling. Hum Mol Genet 2009;18(23):4565-75

[103] Abdelhamed ZA, Wheway G, Szymanska K, Natarajan $\mathrm{S}$, Toomes $\mathrm{C}$, Inglehearn $\mathrm{C}$, et al. Variable expressivity of ciliopathy neurological phenotypes that encompass Meckel-Gruber syndrome and Joubert syndrome is caused by complex de-regulated ciliogenesis, Shh and Wnt signalling defects. Hum Mol Genet 2013;22(7):1358-72.

[104] Putoux A, Thomas S, Coene KL, Davis EE, Alanay Y, Ogur G, et al. KIF7 mutations cause fetal hydrolethalus and acrocallosal syndromes. Nat Genet 2011;43(6):601-6.

[105] Wheway G, Abdelhamed Z, Natarajan S, Toomes C, Inglehearn C, Johnson CA. Aberrant Wnt signalling and cellular over-proliferation in a novel mouse model of Meckel-Gruber syndrome. Dev Biol 2013;377(1):55-66.

[106] Leightner AC, Hommerding CJ, Peng Y, Salisbury JL, Gainullin VG, Czarnecki PG, et al. The Meckel syndrome protein meckelin (TMEM67) is a key regulator of cilia function but is not required for tissue planar polarity. Hum Mol Genet 2013;22(10):2024-40.

[107] Lancaster MA, Louie CM, Silhavy JL, Sintasath L, Decambre M, Nigam SK, et al. Impaired Wnt-beta-catenin signaling disrupts adult renal homeostasis and leads to cystic kidney ciliopathy. Nat Med 2009;15(9):1046-54.

[108] Lancaster MA, Schroth J, Gleeson JG. Subcellular spatial regulation of canonical Wnt signalling at the primary cilium. Nat Cell Biol 2011;13(6):700-7.

[109] Ozyurek H, Kayacik OE, Gungor O, Karagoz F. Rare association of Hirschsprung's disease and Joubert syndrome. Eur J Pediatr 2008;167(4):475-7. 
[110] Koutsouraki E, Markou E, Karlovasitou A, Costa V, Baloyannis S. Clinical case: Vermis hypoplasia with features of Smith-Lemli-Opitz syndrome. Int J Neurosci 2007;117(4): 443-51.

[111] Casamassima AC, Mamunes P, Gladstone IM Jr, Solomon S, Moncure C. A new syndrome with features of the Smith-Lemli-Opitz and Meckel-Gruber syndromes in a sibship with cerebellar defects. Am J Med Genet 1987;26(2): 321-36.

[112] Lindhout D, Barth PG, Valk J, Boen-Tan TN. The Joubert syndrome associated with bilateral chorioretinal coloboma. Eur J Pediatr 1980;134(2):173-6.

[113] Lopez E, Thauvin-Robinet C, Reversade B, Khartoufi NE, Devisme L, Holder M, et al. C5orf42 is the major gene responsible for OFD syndrome type VI. Hum Genet 2014;133(3):367-77.

[114] Moerman P, Pauwels P, Vandenberghe K, Lauweryns JM, Fryns JP. Goldston syndrome reconsidered. Genet Couns 1993;4(2):97-102.

[115] Khanna H, Davis EE, Murga-Zamalloa CA, EstradaCuzcano A, Lopez I, den Hollander AI, et al. A common allele in RPGRIP1L is a modifier of retinal degeneration in ciliopathies. Nat Genet 2009;41(6):739-45.

[116] Louie CM, Caridi G, Lopes VS, Brancati F, Kispert A, Lancaster MA, et al. AHI1 is required for photoreceptor outer segment development and is a modifier for retinal degeneration in nephronophthisis. Nat Genet 2010;42(2):175-80.
[117] MacArthur DG, Manolio TA, Dimmock DP, Rehm HL Shendure J, Abecasis GR, et al. Guidelines for investigating causality of sequence variants in human disease. Nature 2014;508(7497):469-76.

[118] Fokkema IF, Taschner PE, Schaafsma GC, Celli J, Laros JF, den Dunnen JT. LOVD v.2.0: The next generation in gene variant databases. Hum Mutat 2011;32(5):557-63.

[119] McIntyre JC, Davis EE, Joiner A, Williams CL, Tsai IC, Jenkins PM, et al. Gene therapy rescues cilia defects and restores olfactory function in a mammalian ciliopathy model. Nat Med 2012;18(9):1423-8

[120] Davis EE, Zhang Q, Liu Q, Diplas BH, Davey LM, Hartley $\mathrm{J}$, et al. TTC21B contributes both causal and modifying alleles across the ciliopathy spectrum. Nat Genet 2011;43(3): 189-96.

[121] Chaki M, Airik R, Ghosh AK, Giles RH, Chen R, Slaats GG, et al. Exome capture reveals ZNF423 and CEP164 mutations, linking renal ciliopathies to DNA damage response signaling. Cell 2012;150(3):533-48.

[122] Bergmann C, Fliegauf M, Brüchle NO, Frank V, Olbrich $\mathrm{H}$, Kirschner J, et al. Loss of nephrocystin-3 function can cause embryonic lethality, Meckel-Gruber-like syndrome, situs inversus, and renal-hepatic-pancreatic dysplasia. Am J Hum Genet 2008;82(4):959-70. 